\title{
Human papillomavirus detection in cervical scrapes from women attended in the Family Health Program ${ }^{1}$
}

\author{
Everton Faccini Augusto ${ }^{2}$ \\ Larissa Silva dos Santos ${ }^{3}$ \\ Ledy do Horto dos Santos Oliveira ${ }^{4}$
}

Objectives: to survey the prevalence of human papillomavirus, associated risk factors and genotype distribution in women who were referred to cervical cancer screening when attended in a Family Health Program. Method: we conducted a cross-sectional survey, investigating 351 women. Polymerase chain reaction for DNA amplification and restriction fragment length polymorphism analysis were used to detect and typify the papillomavirus. Results: virus infection was detected in $8.8 \%$ of the samples. Among the 21 different genotypes identified in this study, 14 were high risk for cervical cancer, and the type 16 was the most prevalent type. The infection was associated with women who had non-stable sexual partners. Low risk types were associated with younger women, while the high risk group was linked to altered cytology. Conclusion: in this sample attended a Family Health Program, we found a low rate of papillomavirus infection. Virus frequency was associated to sexual behavior. However, the broad range of genotypes detected deserves attention regarding the vaccine coverage, which includes only HPV prevalent types.

Descriptors: Papillomavirus Infections; Genotype; Preventive Health Services.

\footnotetext{
${ }^{1}$ Paper extracted from master's thesis "Infecção por papilomavirus humano e fatores associados a não adesão ao exame de Papanicolau em mulheres atendidas no Programa Médico de Família, Niterói-RJ" presented to Universidade Federal Fluminense, Niterói, RJ, Brazil. Supported by Pró-Reitoria de Pesquisa, Pós-Graduação e Inovação, Universidade Federal Fluminense (FOPESQ/PROPPi-UFF), process \# 23069.051782/2010-36.

${ }^{2}$ MSc, RN, Hospital Estadual Alberto Torres, Secretaria de Estado de Saúde e Defesa Civil do Estado do Rio de Janeiro, Rio de Janeiro, RJ, Brazil. ${ }^{3}$ Doctoral student, Universidade Federal Fluminense, Niterói, RJ, Brasil.

${ }^{4} \mathrm{PhD}$, Full Professor, Departamento de Microbiologia e Parasitologia, Universidade Federal Fluminense, Niterói, RJ, Brazil.
}

\section{Corresponding Author:}

Ledy do Horto dos Santos Oliveira

Universidade Federal Fluminenese. Departamento de Microbiologia e Parasitologia

Rua Profo Ernani Melo, 101

Bairro: São Domingos

CEP: 24210-130, Niterói, RJ, Brasil

E-mail: mipledy@centroin.com.br
Copyright (c) 2014 Revista Latino-Americana de Enfermagem This is an Open Access article distributed under the terms of the Creative Commons Attribution Non-Commercial License (CC BY-NC).

This license lets others distribute, remix, tweak, and build upon your work non-commercially, and although their new works must also acknowledge you and be non-commercial, they don't have to license their derivative works on the same terms. 


\section{Introduction}

The dynamic of human papillomavirus infection in the female genital tract comprises a broad range of events. They include latent, transient, persistent and benign warts, low and high grade squamous lesions and cervical cancer $^{(1)}$. Despite the existence of more than 40 genital and anogenital types, progression to cervical cancer is associated with approximately 15 high risk types $^{(2)}$. Because the progression from normal tissue to malignant disease is continuous and can be delayed until several years after infection, intervening in the early steps of this process will prevent the development of cancer.

The Papanicolau (Pap) cytological test, a low cost exam, allows for the screening, detection and management of neoplastic abnormalities, preventing women from developing malignant disease. The sensitivity of this test is estimated to be approximately $75 \%$ (due to false negatives or false positives), but the use of appropriate screening highly reduces the cervical cancer rates in a covered population ${ }^{(3)}$.

The knowledge that HPV infection is essential for cervical cancer development has led to the implementation of additional strategies in cervical cancer prevention programs. As an effective tool, HPV DNA testing focusing on high-risk types has been considered, which is more sensitive than Pap screening, although it has lower specificity than cytology ${ }^{(4)}$. To improve the accuracy of early detection, triage with HPV DNA tests plus cytology will aid in the early diagnosis of HPV infection, thus protecting women from developing cervical cancer(5). Besides, data about HPV genital infection reveal important aspects of the virus' geographic distribution, which differs across regions and other demographic factors. In Brazil, this test is solely offered through the private healthcare network because it entails higher costs and more logistic support than cytological screening. Hence, the knowledge of HPV infection among women attended public health services has been obtained through regional studies that show the virus and its prevalent genotypes, as well as the cultural factors that act in particular regions of the country. In the HPV vaccine era, such information is useful for vaccination strategies.

According to a Ministry of Health report, the estimated cervical cancer incidence in Brazil for 2012 was 17,540 new cases. Of these, 2,030 cases occurred in the state of Rio de Janeiro(6). Brazilian health policies recommend the cytology-based Papanicolaou test for cervical cancer control at periodic intervals for women aged 25-59 years or after their sexual debut(7). Because the impact of HPV vaccines in cervical cancer is still not entirely known, they are approved for women attending private clinics, but they are not available through the public health system.

Family Health programs that include cervical cancer prevention have been implemented in several cities from the State of Rio de Janeiro. These programs offer preventive screening to women living in these cities at regular intervals. In a previous study, we analyzed 351 women referred to a Family Health Program from Rio de Janeiro state(8). Most of these women (96.3\%) had normal or inflammatory cytology. In order to provide additional data to ratify the cervical cancer control strategies, we surveyed the HPV prevalence in this people in the light of the routine Pap smear screening. We have also investigated the possible co-factors for the infection. In view of large number of HPV types, we determined the frequency of genotypes distribution and grouped the identified types by species.

\section{Method}

We conducted a cross-sectional survey, investigating 351 women who were referred to the Family Health Program from Niterói city, State of Rio de Janeiro, between March 2009 and November 2010. The women included in this work had at least one sexual partner in their lifetime and were registered in the Family Health Program. Pregnancy and hysterectomy were excluding factors. No women were vaccinated against HPV. Demographic data were obtained through a structured household questionnaire. The Ethics Committee of the College of Medicine of the University provided ethical clearance for the protocol and informed consent (CEP CMM/HUAP 052/2010, CAAE 0037.0.258.000-10). This sampling method and the profile of this population has already been described ${ }^{(8)}$. Briefly, they were 17 to 79 years old. Most of them gained a monthly family income superior to U\$600 and $57.3 \%$ had attended only elementary school or reported illiterate conditions. Non white people were the most prevalent ethnic group. Most of the women maintained a stable sexual partner and had up to three sexual partners in the lifetime, with one partner during the last three months. Nearly half began their sexual life before the age of 17 years.

Women were submitted to routine gynecological examination. They attended the service upon their 
own initiative with a previous appointment, or were encouraged by a health care professional to attend their screening. Cervical samples were collected after clinical examination. Two cervical specimens were collected from each participant using a cervical brush. The first sample was spread onto a glass slide to be processed for Papanicolau staining. The remaining specimen, containing ectocervical and endocervical cells, were placed in Tris EDTA buffer (10 mM Tris $\mathrm{pH}$ 7.4, $1 \mathrm{mM}$ EDTA) and stored at $-20^{\circ} \mathrm{C}$ until HPV testing was performed.

According to the Bethesda nomenclature, cervical smears were classified as normal/inflammatory, atypical squamous cells of undetermined significance (ASCUS), low grade squamous intraepithelial lesions (LSIL) or high grade squamous intraepithelial lesions $(\mathrm{HSIL})^{(9)}$.

DNA was extracted from the cervical samples with phenol-chloroform-isoamyl alcohol. MY09/11 consensus primers were used to detect generic HPV DNA. These primers are universal and detect a large number of epithelial and mucosal papillomavirus. HPV typing was performed by restriction fragment length polymorphism analysis (RFLP) following polymerase chain reaction (PCR) DNA amplification. The resultant 450 base pair PCR products were digested by six restriction enzymes (BamHI, DdeI, HaeIII, HinfI, PstI, RsaI; Invitrogen, São Paulo, Brazil). The RFLP pattern of each sample was analyzed by agar gel electrophoresis under ultraviolet light and compared with the RFLP patterns for mucosal HPV(10). HPV types were clustered according to biological and philogenetic criteria(11). Specimens were classified as high risk if they had at least one high risk HPV type, and low risk if they had only low risk HPV types.

A data bank was generated and analyzed using the Epi Info statistical package (version 3.5.1, 2008, CDC). Statistical analyses were performed for laboratory diagnosis, risk and demographic factors for HPV infection. The association between epidemiological variables and HPV was examined by analysis with odds ratios and $\mathrm{p}$ values. To investigate independent associations, variables with $p \leq 0.1$ were included in the multiple logistic regression analyses. $p$ values equal or lower than 0.05 were considered statistically significant.

\section{Results}

Demographic and behavior data have already been described in a previous paper(8).
Women aged 14 to 79 years old, mean age 38.43 year, standard deviation 14.26. We found 282 women above 25 years (64.95\%). Most of them gained a monthly family income superior to U\$600 and $57.3 \%$ had attended only elementary school or reported illiterate conditions. Non white people were the most prevalent ethnic group. Most of the women maintained a stable sexual partner and had up to three lifetime sexual partners, with one partner during the last three months. Nearly half began their sexual life up to the age of 17 years. Sixty-one percent and $55.0 \%$ of the women had never used cigarettes and alcohol. Preservatives were not used by $67.2 \%$ of women and contraceptive methods by $83.5 \%$. Parity until two children was reported by $69.2 \%$ of the women, of whom $32.8 \%$ related abortion episodes. Most of the women $(82.3 \%)$ did not refer to any sexually transmitted diseases (Table 1). Among the remaining women, $23(6.6 \%)$ related clinical symptoms of condyloma, $18(5.1 \%)$ candidiasis, syphilis $14(4.0 \%)$, gonorrhea 3 $(0.9 \%)$, hepatitis B $2(0.6 \%)$, Chlamydia $1(0.3 \%)$, and genital herpes $1(0.3 \%)$.

Most women (338) had normal cytology (96.3\%), five had ASCUS (1.4\%), three had LSIL $(0.9 \%)$, one had HSIL $1(0.3 \%)$ and four were excluded because of inconclusive findings $(1.1 \%)^{(8)}$. HPV infection was present in $8.8 \%$ (31/351) of the samples. As expected, altered cytology was significantly associated with infection (Table 1). However, after adjusted OR, the result lost significance (OR 4.4, CI [0.96-20.48], $\mathrm{p}=0.056)$. Viral infection was less frequent among women who underwent regular Pap screening, but preventive exam at least once during the lifetime did not affect the cytological status. In spite of this, it is remarkable that regular Pap exams lead to a reduction of the virus frequency (Table 1 ).

Women with high and low risk types corresponded to $4.0 \%$ and $4.8 \%$, respectively. High risk HPV genotypes were only strongly associated with cellular changes (OR 14.77, CI [3.26-66.90], $p=0.003)$. This association remained (OR 9.97, CI [2.07-47.85], $p=0.004$ ) in the multivariate model. In spite of this, 11 (3.3\%) women with normal or inflammatory cytology were infected by high risk HPV.

Low risk types were not associated with changes in cytology. However, women who had not undergone regular screening had a greater probability of acquiring low risk HPV types (OR 3.94, CI [1.46-10.64], $\mathrm{p}=0.01$ ). 
Table 1 - HPV positivity versus cytological results and Pap smear screening, Niterói, RJ, Brazil, 2009-2010

\begin{tabular}{|c|c|c|c|c|}
\hline \multirow[b]{2}{*}{ Variables $(\mathrm{N}=351)$} & \multicolumn{2}{|c|}{ HPV infection } & \multirow[b]{2}{*}{ OR (CI 95\%) } & \multirow[b]{2}{*}{$p$ value } \\
\hline & $\begin{array}{c}\text { Positive } \\
\text { n (\%) }\end{array}$ & $\begin{array}{c}\text { Negative } \\
\mathrm{n}(\%)\end{array}$ & & \\
\hline Cytology* & & & & 0.039 \\
\hline ASCUS, LSIL, HSIL & $3(33.3)$ & $6(66.7)$ & $5.75(1.36-24.32)$ & \\
\hline Normal, inflammatory & $27(8.0)$ & $311(92.0)$ & 1 (Ref) & \\
\hline Pap test & & & & 0.080 \\
\hline No & $4(23.5)$ & $13(76.5)$ & $3.49(1.06-11.47)$ & \\
\hline Yes & $27(8.1)$ & 307 (91.9) & 1 (Ref) & \\
\hline Pap test & & & & 0.020 \\
\hline Irregular intervals & $11(15.9)$ & $58(84.1)$ & $2.48(1.12-5.46)$ & \\
\hline Advised intervals & $20(7.1)$ & $262(92.9)$ & 1 (Ref) & \\
\hline
\end{tabular}

Among the demographic variables, the univariate analysis revealed that an age of more than 24 years was a protective factor for infection (Table 2 ). Women who had the same sexual partner for more than one year were less exposed to HPV infection than those who did not have a stable sexual partner, although the frequency of virus infection did not depend on the number of sexual partners during their life or the age of sexual debut (Table 2).
Although not significant, a non-white ethnicity showed a weak trend. The other factors, including schooling and socioeconomic status, were not associated with infection in these people. It was not associated either with preservatives, contraceptive methods, abortion or number of parities. Smoking and alcohol consumption habits failed to demonstrate any association with the detection of HPV DNA (Table 2).

Table 2 - Demographic and lifestyle data for study participants, Niterói, RJ, Brazil, 2009-2010

\begin{tabular}{|c|c|c|c|c|}
\hline \multirow[b]{2}{*}{ Variables $(\mathrm{N}=351)$} & \multicolumn{2}{|c|}{ HPV infection } & \multirow[b]{2}{*}{ OR (CI $95 \%)$} & \multirow[b]{2}{*}{$p$ value } \\
\hline & $\begin{array}{c}\text { Positive } \\
\text { n (\%) }\end{array}$ & $\begin{array}{c}\text { Negative } \\
\text { n (\%) }\end{array}$ & & \\
\hline Civil status & & & & 0.001 \\
\hline Non-stable sexual partners & $19(61.3)$ & $99(30.9)$ & $3.53(1.65-7.56)$ & \\
\hline Living together for $>1$ year & $12(38.7)$ & $221(69.1)$ & 1 (Ref) & \\
\hline Age & & & & 0.011 \\
\hline $15-24$ years & $12(38.7)$ & $57(17.8)$ & $2.94(1.35-6.66)$ & \\
\hline 25 years or older & $19(61.3)$ & $263(82.2)$ & 1 (Ref) & \\
\hline Ethnicity & & & & 0,080 \\
\hline Non-white & $25(80.6)$ & $202(63.1)$ & $2.43(0.97-6.10)$ & \\
\hline White & $6(19.4)$ & $118(36.9)$ & 1 (Ref) & \\
\hline Alcohol drinking & & & & 0.086 \\
\hline Yes & $19(61.3)$ & $139(43.4)$ & $2.04(0.98-4.39)$ & \\
\hline No & $12(38.7)$ & $181(56.6)$ & 1 (Ref) & \\
\hline Number of lifetime sexual partners & & & & 0.116 \\
\hline$>3$ & $15(48.4)$ & $108(33.8)$ & $1.84(0.87-3.86)$ & \\
\hline $1-3$ & $16(51.6)$ & $212(66.2)$ & 1 (Ref) & \\
\hline Contraceptive methods & & & & 0.411 \\
\hline No & $3(9.6)$ & $55(17.2)$ & $0.51(0.15-1.75)$ & \\
\hline Yes & $28(90.4)$ & $265(82.8)$ & 1 (Ref) & \\
\hline Schooling & & & & 0.443 \\
\hline Illiterate & 0 & $15(4.07)$ & $0.90(0.87-0.93)$ & \\
\hline Elementary school or more & $31(100)$ & $305(95.3)$ & 1 (Ref) & \\
\hline Smoking & & & & 0.589 \\
\hline Any time & $14(45.2)$ & $123(38.4)$ & $1.31(0.62-1.72)$ & \\
\hline Never & $17(54.8)$ & $197(61.6)$ & 1 (Ref) & \\
\hline
\end{tabular}


Table 2 - (continuation)

\begin{tabular}{|c|c|c|c|c|}
\hline \multirow[b]{2}{*}{ Variables $(\mathrm{N}=351)$} & \multicolumn{2}{|c|}{ HPV infection } & \multirow[b]{2}{*}{ OR (Cl $95 \%)$} & \multirow[b]{2}{*}{ p value } \\
\hline & $\begin{array}{c}\text { Positive } \\
\text { n (\%) }\end{array}$ & $\begin{array}{c}\text { Negative } \\
\text { n (\%) }\end{array}$ & & \\
\hline Family income & & & & 0.598 \\
\hline$\leq \$ 500.00$ & $13(41.9)$ & $118(37.1)$ & $0.81(0.38-1.72)$ & \\
\hline$>\$ 500.00$ & $18(58.1)$ & $200(62.9)$ & 1 (Ref) & \\
\hline Parity & & & & 0.701 \\
\hline$>3$ & $12(38.7)$ & $141(44.1)$ & $0.80(0.37-1.70)$ & \\
\hline$\leq 3$ & $19(61.3)$ & $179(55.9)$ & 1 (Ref) & \\
\hline First sexual experience & & & & 0,814 \\
\hline$\leq 16$ years & $15(50)$ & $147(45.9)$ & $0.85(0.40-1.79)$ & \\
\hline$>16$ years & $15(50)$ & $173(54.1)$ & 1 (Ref) & \\
\hline Abortion & & & & 0.841 \\
\hline Yes & $9(32.9)$ & 105 (32.9 & $1.19(0.53-2.69)$ & \\
\hline No & $22(71.0)$ & $214(67.1)$ & 1 (Ref) & \\
\hline Current smoking habit & & & & 0.953 \\
\hline Yes & $14(45.2)$ & $123(38.4)$ & $0.91(0.43-1.91)$ & \\
\hline No & $17(54.8)$ & $197(61.6)$ & 1 (Ref) & \\
\hline Preservative use & & & & 1.00 \\
\hline No & $24(77.4)$ & $245(76.6)$ & $1.05(0.43-2.53)$ & \\
\hline Yes & $7(22.6)$ & $24(23.4)$ & 1 (Ref) & \\
\hline
\end{tabular}

To identify independent factors associated with HPV infection, we performed a multiple logistic regression analysis between HPV and covariates with a statistical significance threshold of less than 0.10. The data for the final model are shown in Table 3. HPV infection remained associated with women who had non-stable sexual partners. The remaining factors did not show significance (Table 3).

Table 3 - Adjusted OR for identifying independent variables in HPV infection, Niterói, RJ, Brazil, 2009-2010

\begin{tabular}{lcc}
\hline \multicolumn{1}{c}{ Variables } & Adjusted OR 95\% Cl & p value \\
\hline Non-stable sexual partners & $2.73(1.23-6.05)$ & 0.013 \\
$<25$ years of age & $2.17(0.96-5.00)$ & 0.065 \\
Alcohol consumption & $1.95(0.89-4.24)$ & 0.092 \\
Non-white ethnicity & $1.94(0.75-4.99)$ & 0.168 \\
\hline
\end{tabular}

Although not significant, the rate of infection among positive cases ranged from $41.9 \%$ in ages below 25 years to $5.9 \%$ in women older than 55 years (Figure 1). High risk HPV infections were not age dependent in the dichotomous age distribution, although they were more frequent $(p=0.09)$ and showed more type diversity between 25-35 ages, as shown in Figure 1.

Among the 21 different HPV genotypes identified in this study, 11 were low risk types and 10 belonged to the high risk group. Two infections could not be typed. HPV 16 was the most prevalent type (11.5\% of all typed infections). We found four mixed HPV co-infections $(6,16 ; 6,18 ; 16,52 ; 52,66 ; 61,54)$.

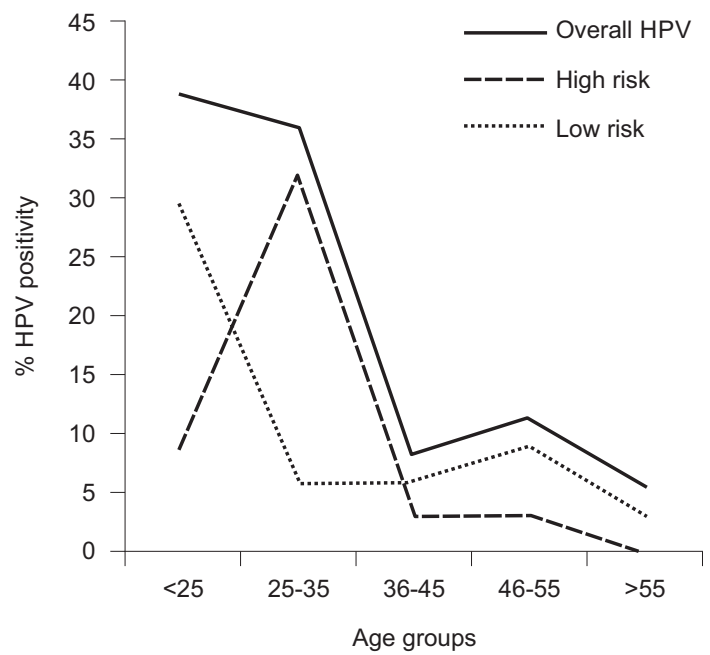

Figure 1 - The prevalence of HPV by age ranges among participants of Family Health Program, Niterói, RJ, Brazil, 2009-2010

The high risk HPV types were classified into A5, A6, A7 and A9 species groups, according to biological and phylogenetic criteria(11), and represented $47.04 \%$ of the individual genotypes. The classical oncogenic species A9 was responsible for one third of the detectable infections and included HPV 16 infections. After clustering the individual genotypes by species, we verified that the low risk types belonged to the $A 3, A 7, A 8, A 10, A 13$ and $A 15$ 
species groups. These genotypes contributed to 52.92\% of the infections.

A9 species were present in almost all age categories, saving the oldest women, who had no high risk infection. A7 species were seen only in the youngest participants.

Concerning low risk HPV types, the prevalence of these genotypes was affected by an age of less than 25 years (OR 7.14, CI [2.5-20], p<0.0001). So, this incidence peak corresponded to HPV infection at younger ages (Figure 1). A10 species, including 6 and 11 types, was not prevalent in this group. One woman over 55 years old had been infected by the uncommon HPV type 40.

\section{Discussion}

This study was carried out to strengthen the knowledge about the HPV genotypes in a female population in the Brazilian Family Health Program. We investigated women who had low risk of HPV infection and cervical cancer development. According to our results, $96.3 \%$ had normal or inflammatory cytology. Even considering the moderate sensibility of Pap test, we verified that $92.9 \%$ of the women submitted to regular Pap test were free from detectable HPV DNA and $96.4 \%$ free from high risk HPV. In addition, among women with normal or inflammatory result, $82.6 \%$ was not infected with HPV. A negative test result indicates a very low chance of a woman to be at risk of developing cancer. Thus, the organized screening program has been successful.

The overall HPV prevalence found in our sample of Brazilian women (8.8\%) was low in comparison with other similar studies ${ }^{(12)}$. In a systematic review of the literature(13), HPV prevalence in Brazil ranged from 13.7 to $54.3 \%$. As the mean age of the sample was over 35 years old and the trend of HPV prevalence was linear and decreased with age, this HPV rate may be explained by the clearance at older ages, prevalent in this sample.

Concerning determinants which affected the HPV positivity, a strong relationship between HPV and nonstable sexual partners was observed and confirmed by regression analysis. Women who had the same sexual partner for more than one year were more probable to avoid infection. However, other lifestyle parameters, such as age at the first sexual experience and number of lifetime sexual partners, were not significant for HPV infection. Considering the cross-sectional characteristic of this study, transient infections could disguise these associations.
The highest frequency of HPV infection was present in women up to 25 years old, consistent with the data already described(14). HPV positivity declined at older ages, probably because younger women were more likely to harbor low risk HPV infections than older women, a significant result that closely relates low risk genotypes with transient infections. The prevalence of overall HPV and low risk types showed a similar distribution, whereas high risk types were distributed in a different epidemiologic profile. A less common low risk HPV 40 was detected in an old woman, perhaps because she should be naïve to such type. Low risk types were spread among six species through all the age groups, strengthening the character of transient infections. Compared with other similar studies in Brazil and worldwide, which indicate the prevalence of high risk HPV at young ages, our results were contrasting(15-17). Oncogenic HPV were solely linked to abnormal cytology, but this event was a consequence rather than a risk factor. We can interpret these data as a result of the persistence of high risk types in cervical cells, regardless of any other variable.

The large number of HPV genotypes found was similar to that observed in other studies performed in the same geographic area. In a previous survey with asymptomatic youngsters, we found 19 HPV types(15), and another related Brazilian study identified 24 types $^{(18)}$. According to the Ministry of Health(7), in Brazil, the most common types found are $16,31,18,6,35,58$, $33,11,54$ and 68 in normal cytology samples; 16, 51, $31,18,58,33,35,39,56$ and 59 in low grade lesions; and $16,11,58,18,31,6,33,45,66$ and 35 in high grade lesions. Less frequent types, such as $52,61,81$ and 84, were found in our study; most of these types belong to the low risk group. This group suggests the transient character of these infections, which are usually cleared by the immune system. Otherwise, most high risk infections belonged to the A9 species, and among them, the HPV 16 genotype was dominant. Among 338 women with normal or inflammatory cytology, 11(3.3\%) harbored high risk HPV. High risk HPV positivity should indicate a need for follow-up to verify the clearance of virus and the non development of abnormal cells. It is worth mentioning that $\mathrm{A} 9$ species were involved in three out of five co-infections.

Currently, immunization against the most common genital HPV types is being used as the primary preventative measure for cervical cancer. Two HPV vaccines, Gardasil ${ }^{\circledR}$ (against types 6, 11 16 and 18 ) and Cervarix ${ }^{\mathrm{TM}}$ (against types 16 and 18) 
target preadolescent children. The current guidelines recommend immunization for those aged from 9 to 26 years $^{(19)}$. It is of interest to inform that, out of 78 young women sexually active at 25 years or less, 5 had at least A7 or A9 HPV genotype. On the other hand, natural seroconversion to HPV 16 or 18 does not protect against other types of same species(20). Considering the local occurrence of such types, women infected with HPV 16 or 18 will continue susceptible to HPV 31,52 , 58 and 59.

In Brazil, the vaccination is in practice only through private clinics. One of the reasons why the government has not yet included the HPV vaccine in the national vaccination program is related to the few oncogenic types covered by the vaccines(21). The development of a second generation multigenic vaccine will maximize HPV protection.

Systematic cervical cancer screening in a public healthcare program with good compliance favors the acquisition of knowledge about the prevention of sexually transmitted infections. We suggest that information and support from basic healthcare staff could be associated with the low rate of HPV infection found in this study. In this way, nurse practitioners have played an important role in answering patients' questions about HPV infection and prevention, regarding women's health.

This study has several limitations. The small size of the sample may produce unstable findings, since the small number of infections can distort the analysis. Cross-sectional design does not permit distinctions between persistent and transient infections. Despite this, the participants were screened for genital HPV through molecular biological assay, complementing the Pap test. HPV DNA is an expensive test, only available in private laboratories. For us, the results provide a basis for studies on the HPV phylogenetic tree and vaccine type variants, which are being developed in our department. Furthermore, offering guidance to women about cancer prevention at the time of the sample collection and interviews was one of the main contributions of the professional staff, focusing on health and education.

\section{Conclusion}

We found, in this sample attended in a Family Health Program, a low rate of papillomavirus infection. However, the broad range of genotypes detected deserves attention regarding the vaccine coverage, which includes only prevalent types.

\section{References}

1. Schiffman M, Wentzensen N, Sholom W, Kinney W, Gage JC, Philip E. Castle PE. Human Papillomavirus Testing in the Prevention of Cervical Cancer. J Natl Cancer Inst. 2011;103(5):368-83.

2. Halfon P, Lindemann MLM, Raimondo A, Ravet S, Camus

$\mathrm{C}$, Khiri H. HPV genotype distribution according to severity of cervical neoplasia using the digene HPV genotyping LQ test. Arch Virol. 2013 June;158(6):1143-9.

3. World Health Organization. Programmes and Projects. Cancer. Screening and early detection of cancer. [Internet]. 2010 [acesso 19 nov 2010]; Disponível em: http://www.who.int/cancer/detection/variouscancer/en/

4. Graham JE, Mishra A. Global challenges of implementing human papillomavirus vaccine. Int J Equity Health. 2011;10(1):27.

5. Wright TC Jr, Schiffman M, Solomon D, Cox JT, Garcia F, Goldie $S$, et al. Interim guidance for the use of human papillomavirus DNA testing as an adjunct to cervical cytology for screening. Obstet Gynecol. 2004;103(2):304-9.

6. Ministério da Saúde (BR). Instituto Nacional do Câncer (INCA). Falando sobre o cancer do colo do útero [Internet]. 59 p. [acesso 17 março 2011. Disponível em bvs/ publicacoes/inca/falando_cancer_colo_utero.pdf

7. Ministério da Saúde (BR). Instituto Nacional do Câncer (INCA). Estimativa (2012). Incidência de câncer no Brasil [Internet]. [acesso 17 jan 2013. Disponível em http://www.inca.gov.br/estimativa/2012

8. Augusto EF, Rosa ML, Cavalcanti SM, Oliveira LH. Barriers to cervical cancer screening in women attending the Family Medical Program in Niterói, Rio de Janeiro. Arch Gynecol Obstet. 2013; 287:53-8.

9. Solomon D, Davey D, Kurman R, Moriarty A, O 'Connor D, Prev M, et al. The 2001 Bethesda System: terminology for reporting results of cervical cytology. JAMA 2002;287(16):2114-9.

10. Bernard HU, Chan SY, Manos MM, Ong CK, Villa LL, Delius $H$, et al. Identification and assessment of known and novel human papillomaviruses by polymerase chain reaction amplification, restriction fragment length polymorphisms, nucleotide sequence, and phylogenetic algorithms. J Infect Dis. 1994;170(5):1077-85.

11. de Villiers EM, Fauquet C, Broker TR, Bernard HU, zur Hausen $\mathrm{H}$. Classification of papillomaviruses. Virology. 2004;324(1):17-27.

12. Silva KC, Rosa ML, Moyses N, Afonso LA, Oliveira LHS, Cavalcanti SMB. Risk factors associated with human papillomavirus infection in two populations 
from Rio de Janeiro, Brazil. Mem Inst Oswaldo Cruz. 2009;104(6):885-91.

13. Ayres AR, Silva GA. Cervical infection in Brazil: systematic review Rev Saúde Pública. 2010;44(5):963-74. 14. Burchell AN, Winer RL, de Sanjosé S. Franco EL. Epidemiology and transmission dynamics of genital HPV infection. Vaccine. 2006;24 Suppl 3:S52-61.

15. Oliveira LHS, Ferreira MDPL, Augusto EF, Melgaço FG, Santos LS, Cavalcanti SMB, Rosa MLG. Human Papillomavirus genotypes in asymptomatic young women from public schools in Rio de Janeiro, Brazil. Rev Soc Bras Med Tropical. 2010;43(1):4-8.

16. Chan PK, Chang AR, Cheung JL, Chan DP, Xu LY, Tang $\mathrm{NL}$, et al. Determinants of Cervical Human Papillomavirus Infection: Differences between High- and Low-Oncogenic Risk Types. J Inf Dis. 2002;185(1):28-35.

17. Naud P, Matos J, Hammes L, Stuckzynski J, Brouwers $\mathrm{K}$, Magno $\mathrm{V}$, et al. Factors predicting intermediate endpoints of cervical cancer and exposure to human papillomavirus (HPV) infections in young women screened as potential targets for prophylactic HPV vaccination in south of Brazil. Eur J Obstet Gynecol Reprod Biol. 2006;124(1):110-8.

18. Oliveira-Silva M, Lordello CX, Zardo LM, Bonvicino CR, Moreira MA. Human Papillomavirus in Brazilian women with and without cervical lesions. Virol J. 2011;8:4.

19. Markowitz LE, Dunne EF, Saraiya M, Lawson HW, Chesson $\mathrm{H}$, Unger ER, et al. Centers for Disease Control and Prevention (CDC); Advisory Committee on Immunization Practices (ACIP): Quadrivalent Human Papillomavirus Vaccine: Recommendations of the Advisory Committee on Immunization Practices (ACIP). MMWR Recomm Rep. 2007;56:1-24.

20. Palmroth J, Merikukka M, Paavonen J, Apter D, Eriksson T, Natunen $\mathrm{K}$, et al. Occurrence of vaccine and non-vaccine human papillomavirus types in adolescent Finnish females 4 years post-vaccination papillomavirus vaccines. Int J Cancer. 2012;131(12):2832-8.

21. Ministério da Saúde (BR). Instituto Nacional do Câncer (INCA). VII Encontro Nacional para o Controle do Câncer do Colo do Útero e de Mama. [Internet]. 2011 [acesso 1 maio 2011]. Disponível em http://www2. inca.gov.br/wps/wcm/connect/agencianoticias/site/ home/noticias/2011/ apresentacoes_do_vii_encontro_ nacional_para_o_controle_do_cancer_do_colo_do_ utero_e_de_mama 